\title{
The Relationship Between Antipsychotic-Induced Akathisia and Suicidal Behaviour: A Systematic Review
}

\author{
Arturas Kalniunas' \\ Ipsita Chakrabarti' \\ Rakhee Mandalia' \\ Jasna Munjiza 2,3 \\ Sofia Pappa ${ }^{1,2}$
}

'West London NHS Trust, London, UK; ${ }^{2}$ Division of Psychiatry, Imperial College London, London, UK; ${ }^{3}$ Central and North West London NHS Foundation Trust, London, UK
Correspondence: Sofia Pappa Recovery Team East, Avenue House, 43-47 Avenue Road, London, W3 8NJ, UK Email sofia.pappa@westlondon.nhs.uk; s.pappa@imperial.ac.uk
Objective: We aim to systematically review evidence for a relationship between antipsychotic-induced akathisia and suicidal behaviour, in order to guide further clinical decision making in this area.

Methods: Several electronic databases (Embase, Medline, Cochrane and PsychINFO) were systemically searched for articles published up to February 2021, using search terms related to akathisia, antipsychotics and suicidal behaviour. Two reviewers independently evaluated all the relevant studies using predetermined criteria and assessed the risk of bias for each included study. The systematic review was conducted in line with PRISMA methodology and reporting.

Results: Following de-duplication, screening and application of exclusion criteria, four eligible studies were identified. All of the available studies were in English and included adult patients. Nevertheless, there was significant variability regarding methodology and overall quality was deemed low due to small sample sizes. There was insufficient data to perform statistical analyses of the results. Of the four studies, two found a weak correlation between antipsychotic-related akathisia and suicidal behaviour, a finding that was not supported by the remaining two studies.

Conclusion: The search yielded very few studies for inclusion. On the basis of the existing evidence, akathisia cannot be reliably linked to the presence of suicidal behaviour in patients treated with antipsychotic medication. However, proactive screening for emerging suicidal behaviour in this vulnerable patient group is advisable. Our findings highlight the pressing need for further research in this area.

Keywords: antipsychotic medication, akathisia, restlessness, suicidal behaviour

\section{Introduction}

Akathisia (Greek "not to sit") is a movement disorder characterized by a subjective, inner sense of restlessness and difficulty in staying still and is often related to the initiation of or rapid escalation of antipsychotic medication. ${ }^{1}$ Akathisia is commonly accompanied by escalated levels of anxiety, agitation and dysphoric affect. The objective component usually entails various semi-purposeful, complex motor activities, such as pacing around, crossing and uncrossing legs, shifting weight from one foot to another, but these may be subtle or absent in some cases. ${ }^{2}$

A reliable assessment and diagnosis of akathisia can be challenging for several reasons. There is no universal consensus on the definition of "case-ness" nor is there an agreement on the relevant significance of its subjective and objective components. In addition, akathisia can manifest in different degrees of severity and have a wide range of 
non-specific motor features. The condition can be easily misdiagnosed - A mild degree of akathisia may be misattributed to psychotic agitation resulting in further escalation of the offending drug. On the other hand, it can co-occur or be caused by other psychiatric and organic conditions (including acute psychosis, comorbid affective disorders, drug withdrawal states, insomnia, delirium), as well as other psychotropic medication, most commonly antidepressants. ${ }^{3,4}$

However, the timely recognition of akathisia is paramount as is it may cause considerable patient distress and may have an impact on treatment outcomes, leading, for example, to nonconcordance and subsequent exacerbation of psychosis. ${ }^{5}$ Poor adherence to treatment, along with other risk factors, such as previous history of depressive disorder, substance misuse, agitation or motor restlessness, have been associated with an increased risk of suicide in patients with schizophrenia. ${ }^{6}$ Furthermore, in one case control study of inpatient suicides, ${ }^{7}$ extrapyramidal side effects (including akathisia) were identified as independent risk factors for completed suicide.

Nevertheless, previous attempts to review ${ }^{4,8}$ potential links between akathisia and emerging suicidal behaviour were not systematic and were mostly based on a limited number of case reports and small case series. The majority of these reports of suicidal ideation, ${ }^{9-11}$ attempted ${ }^{12-14}$ and completed suicides, ${ }^{15,16}$ were associated with the emergence of acute akathisia induced by first generation high potency antipsychotics (summarised in Table 1). Although, it has been suggested that the magnitude of the problem may be even bigger due to underreported cases. ${ }^{8}$

A definitive causal link between antipsychotic induced akathisia and suicidal behaviour has not been established to date, possibly reflecting the complexity of the clinical phenomena of both akathisia and suicidal behaviour. For the purpose of this review, we focussed solely on antipsychotic-induced akathisia and did not include studies of antidepressant-related akathisia, as the mechanisms mediating this relationship may be different. Furthermore, a systematic review on antidepressant-induced akathisia and suicidal behaviour has been previously conducted, ${ }^{17}$ further highlighting the need for a robust literature review in regards to antipsychotic medication.

\section{Aims of the Study}

The main objective of this study was to conduct a systematic review of all available literature in order to assess the evidence supporting or discarding a potential relationship between antipsychotic-induced akathisia and suicidal behaviour.

\section{Methods}

This systematic review adhered to the PRISMA guidelines. ${ }^{18}$

\section{Inclusion and Exclusion Criteria}

Studies were deemed eligible if a) they included adult participants with antipsychotic-induced akathisia, b) the

Table I Summary of Case Studies Supporting Possible Association Between Antipsychotic-Induced Akathisia and Suicidal Behaviour

\begin{tabular}{|c|c|c|}
\hline Study & $\begin{array}{l}\text { Sample } \\
\text { Size }\end{array}$ & Main Findings \\
\hline $\begin{array}{l}\text { Van Putten } \\
\text { et al }\end{array}$ & 3 & 3 cases of suicidal ideation associated with akathisia caused by fluphenazine depot injection. \\
\hline Shear et al ${ }^{15}$ & 2 & 2 cases of completed suicide associated with akathisia in male patients treated with depot fluphenazine \\
\hline $\begin{array}{l}\text { Drake and } \\
\text { Ehrlich }^{12}\end{array}$ & 2 & $\begin{array}{l}\text { Impulsive suicide attempts associated with akathisia in a young man commenced on haloperidol and a young woman } \\
\text { started on fluphenazine depot. }\end{array}$ \\
\hline Shaw et al ${ }^{10}$ & I & $\begin{array}{l}\text { Suicidal and homicidal ideation associated with akathisia in a double blind neuroleptic cross over study - a patient } \\
\text { was switched from experimental drug with low dopamine affinity to haloperidol. }\end{array}$ \\
\hline Schulte ${ }^{16}$ & 5 & $\begin{array}{l}2 \text { cases of suicidal attempts and } 3 \text { cases of homicide as a result of akathisia, following administration of haloperidol } \\
\text { for acute psychotic symptoms. }\end{array}$ \\
\hline $\begin{array}{l}\text { Azhar and } \\
\text { Varma }^{14}\end{array}$ & 3 & $\begin{array}{l}\text { Three cases of emerging suicidal ideation and suicidal attempts attributed to akathisia by patients commenced on } \\
\text { haloperidol. }\end{array}$ \\
\hline Padder et al $^{9}$ & I & I case of new onset suicidal ideation associated with akathisia in male patient treated with low dose of aripiprazole \\
\hline Cheng et al $^{13}$ & I & Patient developed akathisia and attempted suicide shortly after being started on pipothiazine depot injection. \\
\hline
\end{tabular}


diagnosis of akathisia was established using validated rating scales, and c) if a temporal or sequential association between akathisia and the emergence or presence of suicidal behaviour (suicidal ideation, suicide attempts or completed suicide) was considered. All clinical clusters requiring treatment with an antipsychotic medication were taken into account and literature related to "first episode psychosis" was also included. Studies reporting on akathisia due to other possible etiopathogenesis were excluded. Studies which were not in English, reviews, conference abstracts, book chapters or treatment protocols were also excluded.

\section{Search Strategy}

Our search strategy was generated by consensus amongst four independent researchers who agreed search terms and eligibility criteria. The following databases in the "Healthcare Databases Advanced Search" Platform was used - EMBASE, Medline, Cochrane, and PsychINFO inclusive of data from inception to February 2021, using the following terms:

Akathisia OR restless*

AND

Suicid* OR self-harm

AND

Neuroleptic* OR antipsychotic* OR major tranquilizer* OR amisulpride OR aripiprazole OR asenapine OR benperidol OR bromperidol OR cariprazine OR chlorpromazine OR chlorprothixene OR clopenthixol OR clozapine OR dixyrazine OR flupenthixol OR fluphenazine OR fluspirilene OR haloperidol OR iloperidone OR levomepromazine OR lurasidone OR melperone OR olanzapine OR paliperidone OR perazine OR perphenazine OR pimozide OR pipamperone OR promazine OR promethazine OR prothipendyl OR quetiapine OR reserpine OR risperidone OR sertindole OR sulpiride OR thioridazine OR trifluoperazine OR trifluperidol OR triflupromazine OR ziprasidone OR zotepine OR zuclopenthixol.

\section{Study Selection}

After de-duplication, all titles and abstracts were screened. The assessment of study eligibility and data extraction included a search of the Cochrane Database of Systematic Reviews. A hand search of relevant studies was conducted independently by two reviewers. In the event of any disagreement, adjudication was sought with two additional reviewers. Authors were also directly contacted for additional information if needed. For the purpose of our review, full text studies were only considered if they were in English.

\section{Data Extraction and Synthesis}

The data was extracted independently by two reviewers. A PRISMA diagram detailing the study retrieval process is shown in Figure 1. Initially 362 studies fulfilled our search criteria. After de-duplication and screening, only four relevant studies met the predetermined inclusion criteria. All four studies were rated as low quality mainly due to their small sample sizes.

In addition, there was considerable heterogeneity between individual studies including - aims, study designs, interventions, outcome measures; hence, a meta-analysis could not be performed and a narrative approach to synthesizing data from the studies included in this review was used.

\section{Results}

Four studies that met the eligibility criteria were included (Table 2). Of these, two reported an association between antipsychotic-induced akathisia and suicidal behaviour, whereas the other two did not find any correlation. A brief narrative highlighting the main hypotheses and the findings of each of the included studies is outlined below:

Atbasoglu et al $^{19}$ conducted a study involving 68 patients with schizophrenia or schizophreniform disorder, who were treated with either typical or atypical antipsychotic medication. The authors used the Barnes Akathisia Rating Scale (BARS), Brief Psychiatric Rating Scale (BPRS), and Hamilton Rating Scale for Depression (HAM-D). Akathisia was reported in 22 (32\%) patients (when they scored at least 1 in global rating in BARS) and was significantly associated with higher HAM-D ratings for suicidal behaviour, depersonalization, and agitation. However, there were no statistically significant differences in total HAM-D and BPRS scores between the patients with and without akathisia. The further analysis of the dichotomised data (suicidal $(n=15)$ vs non-suicidal) showed that only the depression/anxiety sub-scores in BPRS and subjective components of akathisia (but not objective or global ratings) in BARS were significantly associated with suicidal behaviour. The limitations of the study were a small sample size, the use of a very low threshold for akathisia case definition and the potential contribution of other factors, such as depressive symptoms, anxiety and depersonalisation.

Another study to explore the relationship between akathisia and suicidal behaviour was conducted by Seemuller et al. ${ }^{20}$ In this 8 -week double-blind randomized control trial, a total of 296 patients with first episode 


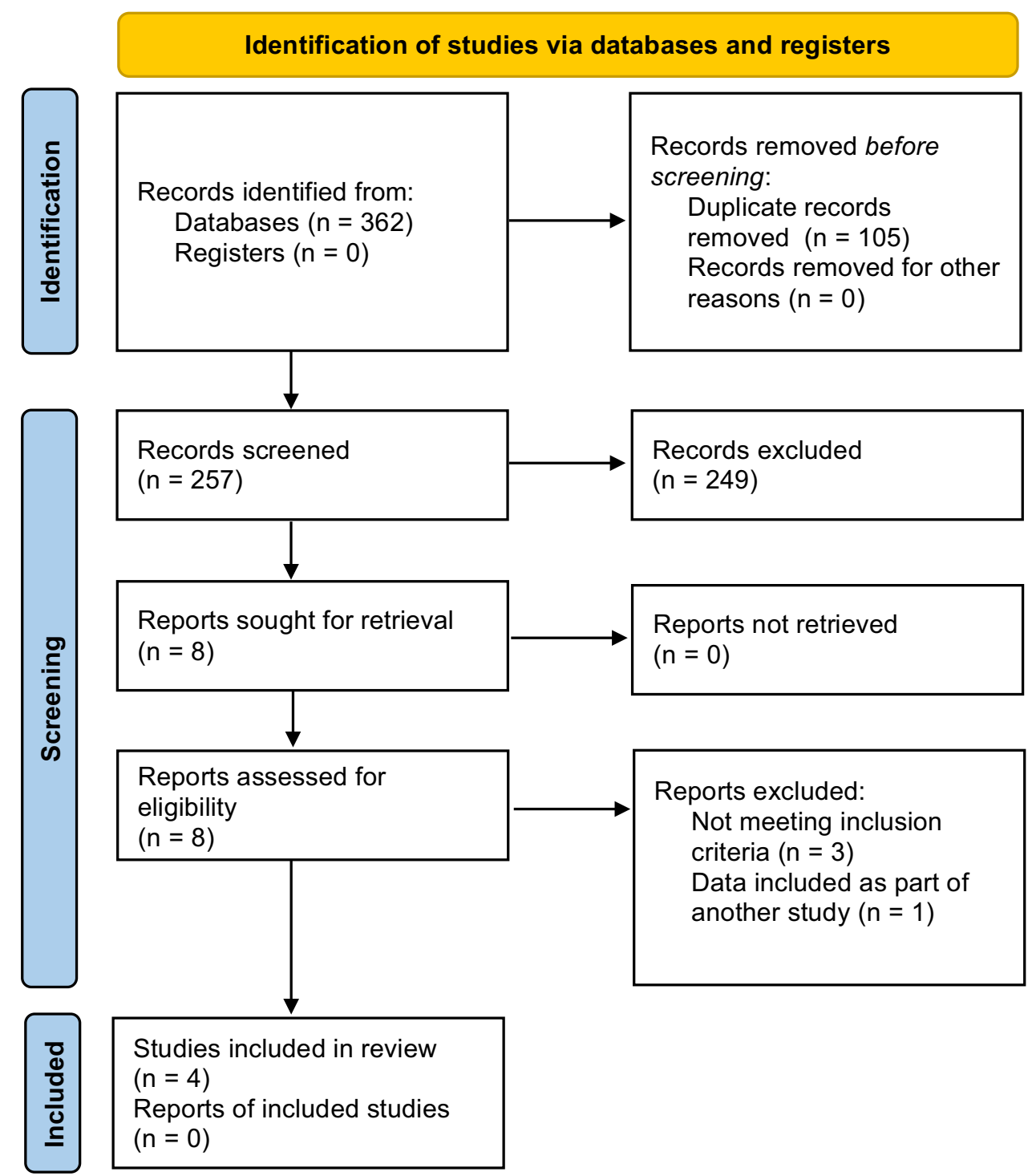

Figure I PRISMA diagram. Adapted from Page MJ, McKenzie JE, Bossuyt PM, et al. The PRISMA 2020 statement: an updated guideline for reporting systematic reviews. BMJ. 2021;372:n7I. Creative Commons license and disclaimer available from: http://creativecommons.org/licenses/by/4.0/legalcode. ${ }^{18}$

psychosis (FEP) were allocated to two treatment arms either on risperidone $(n=148)$ or on haloperidol $(n=148)$. The mean dose of medication for both groups was $4 \mathrm{mg}$. In addition, patients were allowed to use rescue medication biperiden up to $6 \mathrm{mg} / \mathrm{d}$ and propranolol up to $80 \mathrm{mg} / \mathrm{d}$ - in case of EPS and akathisia. Item 3 of the Hamilton Depression Rating Scale (HAMD) and Hillside Akathisia Scale (HAS) were employed for the assessment of suicidal behaviour and akathisia, respectively. Eighteen percent of patients experienced akathisia with the majority being borderline $(10.6 \%)$ or mild $(6 \%)$. The linear regression analysis showed a significant association only between the clinician-rated global akathisia and HAMD score for suicidal behaviour along with depressed mood and use of propranolol; this was not the case for the subjective/self-rated akathisia rating. The log-rank analysis of the time trends between time to maximum akathisia (median - 14 days) and time to maximum score for suicidal behaviour (median - 17 days) did not show any significant differences. Though the authors suggested that there was a correlation between akathisia and suicidal behaviour, they were not able to establish causality between these two clinical phenomena, nor were they able to demonstrate that akathisia precedes suicidal behaviour. They concluded that a much larger sample would be necessary to confirm or reject such hypothesis in the future.

Hansen et $\mathrm{al}^{21}$ published a sub-analysis of a larger RCT that originally compared the differences between manualized CBT and befriending in patients with treatment 
Table 2 Summary of Included Studies

\begin{tabular}{|c|c|c|c|c|}
\hline Study & Design & Sample & Main Findings & $\begin{array}{l}\text { Quality } \\
\text { of } \\
\text { Evidence }\end{array}$ \\
\hline $\begin{array}{l}\text { Cem Atbasoglu } \\
\text { et al }{ }^{19} \text { Turkey }\end{array}$ & $\begin{array}{l}\text { Cross sectional } \\
\text { study }\end{array}$ & $\begin{array}{l}68 \text { patients ( } 49 \text { men and } 19 \text { women) } \\
\text { Mean age: patients with akathisia } 33.2 \\
\text { years, without akathisia }=36.7 \text { years }\end{array}$ & $\begin{array}{l}\text { Significant association between subjective } \\
\text { components of akathisia, symptoms of } \\
\text { depression/ anxiety and suicidality. }\end{array}$ & Low \\
\hline $\begin{array}{l}\text { Seemuller et } \mathrm{al}^{20} \\
\text { Germany }\end{array}$ & $\begin{array}{l}8 \text { week, double- } \\
\text { blind multicenter } \\
\text { RCT }\end{array}$ & $\begin{array}{l}289 \text { patients ( } 117 \text { women and } 172 \text { men) } \\
\text { Mean age: } 30.1 \text { years }\end{array}$ & $\begin{array}{l}\text { Significant correlation between objective } \\
\text { symptoms of akathisia, depressive symptoms } \\
\text { and suicidal ideation in first episode } \\
\text { schizophrenia }\end{array}$ & Low \\
\hline $\begin{array}{l}\text { Hansen et al }{ }^{21} \\
\text { United Kingdom }\end{array}$ & $\begin{array}{l}\text { Sub-analysis of } \\
\text { a RCT }\end{array}$ & $\begin{array}{l}86 \text { at baseline; } 67 \text { at second assessment } \\
\text { Mean age: } 39 \text { years }\end{array}$ & $\begin{array}{l}\text { No significant relationship between akathisia } \\
\text { and depression/suicidality in patients with } \\
\text { treatment resistant schizophrenia }\end{array}$ & Low \\
\hline $\begin{array}{l}\text { Hansen et } \mathrm{al}^{22} \\
\text { United Kingdom }\end{array}$ & $\begin{array}{l}\text { Cross sectional } \\
\text { study }\end{array}$ & $\begin{array}{l}70 \text { patients ( } 54 \text { men; } 16 \text { women) } \\
\text { Mean age: } 38 \text { years }\end{array}$ & $\begin{array}{l}\text { No correlation found between suicidality } \\
\text { and neither akathisia/EPS nor substance } \\
\text { abuse }\end{array}$ & Low \\
\hline
\end{tabular}

resistant schizophrenia. The authors used the data from two separate assessments - one conducted at baseline $(n=86)$ and the other one after completion of treatment $(n=67)$, which could have lasted up to 9 months. The dose of medication was not altered significantly between the assessments, although there was no information provided on the specific treatments. Patients were assessed using item 7 of the Comprehensive Psychopathological Rating Scale (a non-validated scale for suicidal behaviour), the Montgomery-Asberg Depression Rating Scale and the Barnes Akathisia Scale. 38/86 (44.2\%) patients experienced akathisia (scoring at least 1 in BARS) at baseline and 25/42 (59.5\%) patients during their second assessment. Neither of the two assessments revealed any statistically significant differences in suicidal behaviour between patients with and without akathisia. Furthermore, there were no significant associations between akathisia and depressive symptoms, or between subjective distress of akathisia and suicidal behaviour.

A different study conducted by Hansen et $\mathrm{al}^{22}$ included 70 patients (of which $77 \%$ were men) with an established diagnosis of schizophrenia, who had been on treatment with antipsychotic medication (first or second generation). Patients also had a history of substance misuse. The BARS was used for akathisia (at least 2 in global score) and a subscale of the Health of the Nation Outcome Scales to assess suicidal behaviour. The rate of suicidal behaviour was not found to correlate with akathisia (or any other
EPS), although only the global scores of akathisia were analysed. The study did not account for the use of for additional medication, for example antidepressants or anticholinergics, which could have affected overall outcomes.

\section{Discussion}

Despite a vigorous and comprehensive search of available literature, only four studies were identified for inclusion in the systematic review. Results were mostly confined to case reports or case series, often reporting on a very small number of participants. The quality of the included studies was overall low and findings were inconsistent mainly due to methodological issues, potential confounding factors and limited generalisability due to their small non-representative samples.

Of the four studies, two ${ }^{19,20}$ reported a weak correlation between antipsychotic-induced akathisia and suicidal behaviour, although discrepancies were noted between the results. Atbasoglu et al $^{19}$ suggested that subjective symptoms of akathisia were better predictors of suicidal behaviour than the objective symptoms, while Seemuller et $\mathrm{al}^{20}$ found that only global ratings of akathisia were associated with increased suicidal behaviour. Nonetheless, both studies were underpowered and unable to establish a temporal association, that is, whether antipsychotic-induced akathisia precipitates suicidal behaviour. In addition, case definition appears to be problematic in the study by 
Atbasoglu et $\mathrm{al}^{19}$ as patients with borderline/questionable pathology were considered as having akathisia. ${ }^{19}$

The other two studies, ${ }^{21,22}$ included in this systematic review, could not establish any links between akathisia and suicidal behaviour, although they also had significant methodological flaws. One study ${ }^{21}$ originally compared two psychological interventions (CBT vs befriending), which could have potentially ameliorated the effects of akathisia and depression, and the other ${ }^{22}$ did not provide any information around concomitant medication (or other psychopathology), which could have also obscured a possible link between antipsychotic-induced akathisia and suicidal behaviour.

Similar to the two negative studies, another study ${ }^{23}$ (not included in this systematic review as it was only available as a conference abstract) using validated rating scales and actometry to measure limb movements in akathisia, also failed to find any correlation between the intensity of suicidal ideation and subjective or objective components of akathisia. In contrast, a recent study (also available as conference abstract only) conducted by Bjarke et $\mathrm{al}^{24}$ reported an association between self-rated akathisia (using a nonvalidated questionnaire for akathisia) and both depression and suicidal behaviour; a finding that is more in line with the results of the two positive studies ${ }^{19,20}$ included in this systematic review.

Previous attempts to investigate potential links between antipsychotic-related akathisia and suicidal behaviour were limited to mainly case reports and small studies. Hansen et $\mathrm{al}^{4}$ conducted a critical review in 2001 but based on the available evidence was unable to either confirm or unequivocally exclude an association between antipsychotic inducedakathisia and suicidal behaviour. Another review published in the same year by Margolese et al, ${ }^{8}$ highlighted the fact that akathisia may be underreported in the existing literature and may, therefore, represent a true risk factor for suicide in schizophrenia.

It is worth noting, that in three out of the four included studies, ${ }^{19,21,22}$ patients were receiving long-term antipsychotic treatment. It has been shown that younger and, particularly, antipsychotic naive patients are more susceptible to side effects. ${ }^{25}$ This appears to be the case for the majority of the published case reports, ${ }^{10-16}$ where mostly young patients were reported to have developed akathisia almost immediately after the initiation of high potency first-generation antipsychotics. Nearly half of the cases of suicidal behaviour were associated with first generation long-acting depot antipsychotics, as described in Table 1.
In addition, in a small case series study of 10 patients with first episode of psychosis, Seemuller et $\mathrm{al}^{26}$ found a close association between rapid-dose escalation and emerging suicidal ideation. In three patients both clinician and self-rated akathisia coincided with emerging suicidal ideation, whereas in two cases only self-rated akathisia revealed a temporal association. Authors highlighted that patient subjective complaints of akathisia should be considered as equally important as the objective signs, as it may help prevent serious harm in this high-risk patient group.

It has been also suggested that acute akathisia may cause a higher degree of inner restlessness compared to chronic akathisia. $^{27}$ Sandyk et $\mathrm{al}^{28}$ attempted to investigate the association between chronic akathisia and previous suicidal attempts in patients with chronic schizophrenia. They found that the severity of akathisia was higher in the group with a history of suicidal behaviour compared to patients with no history. However, due to its retrospective design it was unclear whether patients were experiencing akathisia around the time of their suicidal attempt. Furthermore, other risk factors, such as depression, were not controlled for. Similarly, a fairly recent population-based nested control study by Reutfors et al, ${ }^{29}$ looked at the life time EPS history in patients with schizophrenia or schizoaffective disorder who had died of suicide within 5-year period from their initial diagnosis. Eighty-four patients were identified and matched individually with one control from the same study population ( $\mathrm{N}=4000)$. Interestingly, they found a significantly lower suicide risk for patients with a history of extrapyramidal side effects (aOR 0.33 , 95\% CI $0.12-$ 0.94); although akathisia was associated with a non-significantly increased suicide risk (aOR 1.21, 95\% CI 0.44-3.33) in the absence, however, of any information relating to polypharmacy, adherence to treatment, medication changes or EPS status prior to completed suicide. Due to its retrospective design, authors could not obtain information around the means of assessment of akathisia or a clear chronology of events, which could have suggested a temporal or sequential association with completed suicide. Unfortunately, none of the studies included in this systematic review, differentiated akathisia to chronic and acute subtypes. However, considerations of such distinction might be useful in future longitudinal studies.

Finally, in this systematic review, we have specifically looked into antipsychotic-induced akathisia and not related to antidepressants, where a separate review and meta-analysis had been already performed. ${ }^{17}$ Interestingly, it could 
not establish any relationship between treatment-emergent adverse effects (including akathisia) and suicidal behaviour in patients treated with antidepressants versus placebo. However, it appears that the analysed clinical trials did not consistently differentiate between suicidal behaviour related to the depressive illness itself and suicidal behaviour associated with medication side effects. A review of 107 articles by Sinclair et $\mathrm{al}^{30}$ (2009) concluded that an antidepressant-induced jitteriness/anxiety syndrome continues to be poorly characterized and its potential impact on suicide rates has not been sufficiently assessed. In addition, another more recent systematic review and meta-analysis (Sharma et al) ${ }^{31}$ highlighted serious limitations in the antidepressant clinical trials and clear evidence of under-reporting of serious harms and adverse events, including akathisia. The authors of the study could not find any significant increase of suicides in association with antidepressants in adult age group, however they highlighted that the true risk of serious harms remains uncertain.

Moreover, given that depression is a well-established risk factor for suicide, it would seem important to explore whether an inter-correlation between akathisia, depressive symptoms and impulsiveness may account for emerging suicidal behaviour rather than akathisia alone in patients with psychosis. ${ }^{1}$ On the other hand, establishing the origin of depressive symptoms can be complicated, as they may be directly caused by akathisia, related to the psychotic illness or due to potential dysphoric effects of antipsychotic medication. ${ }^{32-34}$ Notwithstanding this, different antipsychotic medication can have variable effects on depression ${ }^{35}$ and depressive symptoms are frequently present prior to the commencement of pharmaceutical treatment. ${ }^{36}$

\section{Strengths and Limitations of Our Review}

To our knowledge, this is the first systematic review to evaluate the relationship between antipsychotic inducedakathisia and suicidal behaviour. Despite a robust and comprehensive search strategy, the search yielded very few eligible studies. One of the key limitations was their small sample size, which could have contributed to significant outcome variability between the studies. In addition, included studies were of low quality and heterogeneous with regards to methodology, case definition and assessment scales; hence, our review emphasised the lack of relevant literature and a number of limitations in the study design of the existing studies.

It is indeed concerning that this alarming side effect remains potentially under-diagnosed and under-reported. Our findings clearly highlight the paucity of evidence thus far and it is hoped that this systematic review will help emphasize both the importance of patient experience and shared decision making in medication in clinical practice $^{37}$ as well the need to prioritise funding and coproduced, participatory research in this area together with service users, carers and clinicians. ${ }^{38}$

\section{Conclusion}

On the basis of the limited evidence available, akathisia cannot be reliably linked to the presence of suicidal behavior in patients treated with antipsychotic medication. Furthermore, due to the paucity of high-quality studies, no firm conclusions can be drawn following this systematic review and a possible relationship cannot be discarded either. Nevertheless, the prevention, identification, and timely management of akathisia remain essential, and proactive screening for emerging suicidal behaviour in this vulnerable patient group is advisable. Finally, our findings highlight the pressing need for further research in this area, preferably studies with more robust methodology and adequate sample size.

\section{Data Sharing Statement}

The data that support the findings of this study are available from the corresponding author upon request. They are all already in the public domain within the included studies.

\section{Author Contributions}

All authors made a significant contribution to the work reported, whether that is in the conception, study design, execution, acquisition of data, analysis and interpretation; took part in drafting, revising or critically reviewing the article; gave final approval of the version to be published; have agreed on the journal to which the article has been submitted; and agree to be accountable for all aspects of the work.

\section{Disclosure}

Dr Sofia Pappa reports grants and/or personal fees from Recordati, Sunovion, Janssen, and NIHR, outside the submitted work. All authors report no other conflicts of interest in this work. 


\section{References}

1. Poyurovsky M. Acute antipsychotic-induced akathisia revisited. $\mathrm{Br}$ J Psychiatr. 2010;196(2):89-91. doi:10.1192/bjp.bp.109.070540

2. Salem H, Nagpal C, Pigott T, Teixeira A. Revisiting antipsychotic-induced akathisia: current issues and prospective challenges. Curr Neuropharmacol. 2017;15(5). doi:10.2174/ 1570159x14666161208153644

3. Kane JM, Fleischhacker WW, Hansen L, Perlis R, Pikalov A, Assunção-Talbott S. Akathisia: an updated review focusing on second-generation antipsychotics. $J$ Clin Psychiatry. 2009;70 (5):627-643. doi:10.4088/JCP.08r04210

4. Hansen L. A critical review of akathisia, and its possible association with suicidal behaviour. Human Psychopharmacol. 2001;16 (7):495-505. doi:10.1002/hup.325

5. Berardi D, Giannelli A, Barnes T. Clinical correlates of akathisia in acute psychiatric inpatients. Int Clin Psychopharmacol. 2000;15 (4):215-219. doi:10.1097/00004850-200015040-00004

6. Hawton K, Sutton L, Haw C, Sinclair J, Deeks J. Schizophrenia and suicide: systematic review of risk factors. Br J Psychiatr. 2005;187 (1):9-20. doi:10.1192/bjp.187.1.9

7. Dong J, Ho T, Kan C. A case-control study of 92 cases of in-patient suicides. $J$ Affect Disord. 2005;87(1):91-99. doi:10.1016/j. jad.2005.03.015

8. Margolese HC, Chouinard G, Walters-Larach V, Beauclair L. Relationship between antipsychotic-induced akathisia and tardive dyskinesia and suicidality in schizophrenia: impact of clozapine and olanzapine. Acta Psychiatr Belg. 2001;101(January):128-144.

9. Padder T, Skodnek K, Hashmi S, et al. Acute akathisia with suicidal ideation associated with low dose aripiprazole. Psychiatry (Edgmont). 2006;3(4):40-43.

10. Shaw E, Mann J, Weiden P, Sinsheimer L, Brunn R. A case of suicidal and homicidal ideation and akathisia in a double-blind. J Clin Psychopharmacol. 1986;6(3):196. doi:10.1097/00004714198606000-00024

11. Van Putten T. Phenothiazine-induced decompensation. Arch Gen Psychiatry. 1974;30(1):102. doi:10.1001/archpsyc.1974.017600 70080012

12. Drake R, Ehrlich J. Suicide attempts associated with akathisia. Am J Psychiatr. 1985;142(4):499-501. doi:10.1176/ajp.142.4.499

13. Cheng H, Park J, Hernstadt D. Akathisia: a life-threatening side effect of a common medication. Case Rep. 2013;2013(may21 1): bcr2012007713. doi:10.1136/bcr-2012-007713

14. Azhar M, Varma S. Akathisia-induced suicidal behaviour. Eur Psychiatr. 1992;7(5):239-241. doi:10.1017/s0924933800003497

15. Shear M, Frances A, Weiddn P. Suicide associated with akathisia and depot fluphenazine treatment. J Clin Psychopharmacol. 1983;3 (4):235. doi:10.1097/00004714-198308000-00006

16. Schulte JL. Homicide and suicide associated with akathisia and haloperidol. Am J Forensic Psychiatr. 1985;6(2):3-7.

17. Tollefson G, Rampey A, Beasley C, Enas G, Potvin J. Absence of a relationship between adverse events and suicidality during pharmacotherapy for depression. J Clin Psychopharmacol. 1994;14 (3):163-169. doi:10.1097/00004714-199406000-00003

18. Page MJ, McKenzie JE, Bossuyt PM, et al. The PRISMA 2020 statement: an updated guideline for reporting systematic reviews. BMJ. 2021;372:n71. doi:10.1136/bmj.n71

19. Cem Atbaşoglu E, Schultz S, Andreasen N. The relationship of akathisia with suicidality and depersonalization among patients with schizophrenia. $J$ Neuropsychiatry Clin Neurosci. 2001;13 (3):336-341. doi:10.1176/jnp.13.3.336
20. Seemüller F, Schennach R, Mayr A, et al. Akathisia and suicidal ideation in first-episode schizophrenia. J Clin Psychopharmacol. 2012;32(5):694-698. doi:10.1097/jcp.0b013e3182677958

21. Hansen L, Jones R, Kingdon D. No association between akathisia or parkinsonism and suicidality in treatment-resistant schizophrenia. $J$ Psychopharmacol. 2004;18(3):384-387. doi:10.1177/026988 110401800309

22. Hansen L, Nausheen B, Hart D, Kingdon D. Movement disorders in patients with schizophrenia and a history of substance abuse. Human Psychopharmacol. 2013;28(2):192-197. doi:10.1002/hup.2305

23. Mlodozeniec A, Jarema M, Szafranski T, Leszczynska A, Krysiak K, Zebrowska A. P.3.a.036 Drug-induced akathisia and suicidal ideation in schizophrenia inpatients. Eur Neuropsychopharmacol. 2009;19: S501. doi:10.1016/s0924-977x(09)70791-6

24. Bjarke J, Gjerde H, Løberg E, Jørgensen H, Kroken R, Johnsen E. M47. Akathisia and atypical antipsychotics: exploring associations to suicidality and agitation. Schizophr Bull. 2020;46(Supplement_1): S151. doi:10.1093/schbul/sbaa030.359

25. Casey DE. Pathophysiology of antipsychotic drug-induced movement disorders. J Clin Psychiatry. 2004;65(Suppl 9):25-28.

26. Seemüller F, Lewitzka U, Bauer M, et al. The relationship of Akathisia with treatment emergent suicidality among patients with first-episode schizophrenia treated with haloperidol or risperidone. Pharmacopsychiatry. 2012;45(7):292-296. doi:10.1055/s-00321309004

27. Sachdev P. Akathisia and Restless Legs. Cambridge, UK: Cambridge University Press; 1995:49-50, 162.

28. Sandyk R, Kay S, Awerbuch G, Iacono R. Risk factors for neuroleptic-induced movement disorders. Int J Neurosci. 1991;61 (3-4):149-188. doi:10.3109/00207459108990737

29. Reutfors J, Clapham E, Bahmanyar S, et al. Suicide risk and antipsychotic side effects in schizophrenia: nested case-control study. Hum Psychopharmacol. 2016;31(4):341-345. doi:10.1002/hup.2536

30. Sinclair LI, Christmas DM, Hood SD, et al. Antidepressant-induced jitteriness/anxiety syndrome: systematic review. $\mathrm{Br} J$ Psychiatry. 2009;194(6):483-490. doi:10.1192/bjp.bp.107.048371

31. Sharma T, Guski LS, Freund N, Gøtzsche PC. Suicidality and aggression during antidepressant treatment: systematic review and meta-analyses based on clinical study reports. BMJ. 2016;352:i65. doi:10.1136/bmj.i65

32. Singh MM, Kay SR. Dysphoric response to neuroleptic treatment in schizophrenia: its relationship to autonomic arousal and prognosis. Biol Psychiatry. 1979;14(2):277-294.

33. Van Putten T, Marder SR. Behavioral toxicity of antipsychotic drugs. J Clin Psychiatry. 1987;48:13-19.

34. Newcomer JW, Miller LS, Faustman WO, Wetzel MW, Vogler GP, Csernansky JG. Correlations between akathisia and residual psychopathology: a by-product of neuroleptic-induced dysphoria. $\mathrm{Br}$ J Psychiatry. 1994;164(6):834-838. doi:10.1192/bjp.164.6.834

35. Aguilar EJ, Siris SG. Do antipsychotic drugs influence suicidal behavior in schizophrenia? Psychopharmacol Bull. 2007;40(3):128-142.

36. Siris SG. Suicide and schizophrenia. J Psychopharmacol. 2001;15 (2):127-135. doi:10.1177/026988110101500209

37. Pappa S, Barnett J, Gomme S, et al. Shared and supported decision making in medication in a mental health setting: how far have we come? Community Ment Health J. 2021;57(8):1566-1578. doi:10.1007/s10597-021-00780-2

38. Dewa LH, Lawrence-Jones A, Crandell C, et al. Reflections, impact and recommendations of a co-produced qualitative study with young people who have experience of mental health difficulties. Health Expect. 2021;24(S1):134-146. doi:10.1111/hex.13088 


\section{Publish your work in this journal}

Neuropsychiatric Disease and Treatment is an international, peerreviewed journal of clinical therapeutics and pharmacology focusing on concise rapid reporting of clinical or pre-clinical studies on a range of neuropsychiatric and neurological disorders. This journal is indexed on PubMed Central, the 'PsycINFO' database and CAS, and is the official journal of The International Neuropsychiatric Association (INA). The manuscript management system is completely online and includes a very quick and fair peer-review system, which is all easy to use. Visit http://www.dovepress.com/testimonials.php to read real quotes from published authors.

Submit your manuscript here: https://www.dovepress.com/neuropsychiatric-disease-and-treatment-journal 